\title{
Response to: Cytokine profile of autologous conditioned serum for treatment of osteoarthritis, in vitro effects on cartilage metabolism and intra-articular levels after injection
}

\author{
Carsten Moser* \\ See related research by Rutgers et al., http://arthritis-research.com/content/12/3/R114 and related letter by Rutgers et al., \\ http://arthritis-research.com/content/12/6/411
}

We welcome the interest of Rutgers and colleagues [1] in providing additional information on the mode of action of autologous conditioned serum (ACS). Studies such as the one they published in a recent issue of Arthritis Research \& Therapy are important because the Orthokine ACS treatment (Orthogen, Düsseldorf, Germany) has been shown to be safe and effective in a number of clinical studies and is used widely in Europe. Randomized controlled trials have confirmed the efficacy of this treatment in osteoarthritis of the knee and lumbar radiculopathy. Additional human studies show promise in treating muscle injury and tunnel widening after anterior cruciate ligament (ACL) reconstruction. All clinical and preclinical studies confirm an excellent riskto-benefit ratio. We would like to offer some comments concerning the paper of Rutgers and colleagues.

The method of producing ACS has been carefully optimized to enrich for anti-inflammatory cytokines, such as interleukin (IL)-1Ra, IL-10, and IL-13, while keeping low the concentration of inflammatory cytokines, such as IL-1 $\beta$ and tumor necrosis factor-alpha (TNF- $\alpha$ ). The ACS preparation of Rutgers and colleagues had increased concentrations of IL- $1 \beta$ and TNF- $\alpha$, and this raises questions about the composition of the product that was tested.

Nevertheless, despite the elevated concentrations of these two cytokines, there was no adverse effect of ACS on proteoglycan turnover in the cartilage explant cultures. This suggests that anti-inflammatory and possibly chondroprotective ingredients within ACS predominate. Further studies using additional controls and autologous instead of heterologous serum would be interesting.

\footnotetext{
*Correspondence: moser@microtherapy.de

Groenemeyer Institute for Microtherapy, Universitaetsstrasse 142, 44799 Bochum, Germany
}

The third component of the study by Rutgers and colleagues measured cytokine levels in synovial fluids before and after treatment with ACS. No changes were found, but it should be noted that Orthokine should be used only when knee effusion has been removed effectively. The described possible aspiration of synovial fluid after treatment with ACS raises questions about the selection of these patients or the composition of the injected ACS. In this regard, it is worth noting that another study [2,3] involving the injection of Orthokine ACS into knees after ACL plasty showed evidence of reduced IL- $1 \beta$ content in synovial fluid. This reduction corresponded with improved pain and function and with reduced tunnel widening. Clearly, the mechanisms through which ACS brings about clinical improvement are incompletely understood and should be the subject of additional research.

\section{Abbreviations}

$\mathrm{ACL}$, anterior cruciate ligament; ACS, autologous conditioned serum; IL, interleukin; TNF-a, tumor necrosis factor-alpha.

\section{Competing interests}

The author declares that he has no competing interests.

Published: 17 December 2010

\section{References}

1. Rutgers M, Saris DBF, Dhert WJA, Creemers LB: Cytokine profile of autologous conditioned serum for treatment of osteoarthritis, in vitro effects on cartilage metabolism and intra-articular levels after injection. Arthritis Research Ther 2010, 12:R114.

2. Darabos N, Hundric-Haspl Z, Haspl M, Markotic A, Darabos A, Moser C: Correlation between synovial fluid and serum IL-1 beta levels after $A C L$ surgery-preliminary report. Int Orthop 2009, 33:413-418.

3. Moser C, Darabos N, Hundric-Haspl Z, Haspl M, Markotic A, Darabos A: Intraarticular Application of Autologous Conditioned Serum (ACS/ Orthokine) reduces bone tunnel widening and improves clinical outcome after ACL reconstructive surgery. In Transactions of the 55th Annual Meeting of the Orthopaedic Research Society Meeting. Las Vegas, USA. Abstract 1463.

\section{doi:10.1186/ar3146}

Cite this article as: Moser C: Response to: Cytokine profile of autologous conditioned serum for treatment of osteoarthritis, in vitro effects on cartilage metabolism and intra-articular levels after injection. Arthritis Research \& Therapy 2010, 12:410. 